"historico-encyclopaedist tradition", and that is a reasonable characterization. The information is here, but barely. Kepler, for example, rates a sentence on page 64 , in reference to his study of the nova of 1604 , and on page 85 , a mention of the same study. Priestley, perhaps more central to the history of chemistry than Kepler, gets one sentence on page 130 and two sentences on page 162 , no more. So we cannot look here for illumination on what made the great scientists work, where they got their ideas, or what prejudices coloured their work. Why, for example, was Lord Kelvin unwilling to accept a great age for the Earth? Was it a religious bias, conscious or unconscious, or did he have a low opinion of geologists? Why did a brilliant geophysicist like Sir Harold Jeffreys totally fail to imagine any way that continents could drift? Was his opposition to drift a consequence of some long ago squabble in the common room or a deeply felt faith in an unchanging Earth?

Questions such as these should be the stuff of science history, not a catalogue of ideas and their contributors. We gain a better understanding of the science of our day and its likely limitations from a consideration of the social and cultural factors that caused spectacular errors by the giants on whose shoulders we stand. This attitude to history, exemplified by much of the writing of Stephen Jay Gould, calls for attention to historical detail, detail that the reader will not find in this book.

On the other hand, the 'historico-encyclopaedic tradition', in this manifestation, fails also to describe the origin of elements, molecules and living systems in sufficient detail to educate readers not already familiar with the science. A journey from 'the chemical elements in nineteenth-century science' to 'biomolecular handedness' by way of nucleosynthesis, origins of planetary systems, chemiosmosis and prebiotic chemistry is too long for 284 pages of text, when these pages must present history as well as science. The result is indeed an encyclopaedia, offering thumbnail sketches of important results and important scientists, not a book from which to learn science or history.

Furthermore, this is not an easy book to read. Admittedly, much of the material is difficult, but the language is also unnecessarily difficult. In the last paragraph of the introduction, a paragraph that is in no way special, the average number of syllables per word is two. For comparison, the last paragraph of the first chapter of Gould's book, Wonderful Life: The Burgess Shale and the Nature of History (Norton, 1989), another technical treatment of difficult science history, has on average 1.35 syllables per word. Which paragraph is more fun to read?

James C. G. Walker is in the Department of Atmospheric, Oceanic and Space Sciences and the Department of Geological Sciences at The University of Michigan, Ann Arbor, Michigan 48109, USA.

\section{Memory's Holy Grail}

\section{Stuart Sutherland}

In The Palaces of Memory: How We Build The Worlds Inside Our Heads. By George Johnson. Knopf: 1991. Pp.255. $\$ 22.95$.

WrTH the same zeal that mediaeval knights devoted to the search for the Holy Grail, neuroscientists have been seeking the engram, the physiological change underlying memory. The comparison is not inapt. Just as the discovery of the cup from which Jesus sipped would not alter Christian doctrine, so the discovery of the engram would scarcely change the way we think about memory: knowing how a transistor works is irrelevant to understanding computer programs, and it is how memory is programmed that is of most interest. Moreover, according to George Johnson's account, the jousting between the scientists bent on the quest for the engram has been at least as formidable and rather more acrimonious than that in which ancient knights participated. Finally, both quests have met with a marked lack of success.

In The Palaces of Memory records scientific discoveries by concentrating on the careers of one or two scientists; it intersperses accounts of their work with reasonably entertaining gossip. The protagonist of the first half of the book is Gary Lynch, a rebel who "hated school" and who rather than attending talks at conferences would hold "drinkathlons" with his acolytes. On a rather flimsy empirical basis, he speculated that when a neuron is fired, calcium channels open, the calcium that pours into the cell activates a substance called calpain, which attacks the cell's cytoskeleton, a structure that supports the cell membrane. Finally, the weakened membrane allows hidden and therefore inactive receptors to pop through: their presence on the surface of the dendrites makes the cell more receptive to stimulation. Lynch attempted to support this ingenious story by a series of no less ingenious but largely inconclusive experiments. His theoretical edifice eventually collapsed when it was shown in another laboratory that he had misinterpreted one of his most crucial experiments: he had mistakenly concluded that at synapses where learning was assumed to have occurred there was an increase in the amount of neurotransmitter binding to receptors (which would of course occur if the learning mechanism was determined by an increase in receptors). Lynch modified his theory and lived to fight another day.

Johnson's account of Lynch and his work is gripping. It gives the layman and scientists in other disciplines an idea of the almost incredible complexity of the nerve cell and synapse, and of the vast number of biochemicals involved. By comparison, the transistor is child's play. One wonders what the function of such complexity can be and marvels that when there is so much to go wrong, the mechanisms are for the most part so reliable.

Despite the fascination of the story of Lynch (which I have greatly truncated), looking at a scientific field through the eyes of one man can be misleading. Many other scientists have been seeking the engram, and their work may prove at least as important as Lynch's; Johnson either mentions them rather casually or ignores them altogether. The one exception is Eric Kandel, of whom Johnson remarks, "some of his colleagues attributed his success less to the merits of his theories than to his abilities at intellectual salesmanship". Kandel worked on the sea slug, a lowly beast with only about 20,000 neurons in its central nervous system. $\mathrm{He}$ proposed a model of the engram in which the change is in the presynaptic neuron not, as Lynch suggested, the postsynaptic one. There are now several different theories of the engram, none of which is satisfactory. Moreover, there is no reason to believe that it will turn out to be the same in all phyla or even in all parts of the human brain.

Johnson goes on to discuss neural nets, basing much of his account on Leon Cooper, who although one of the first in the field has hardly been the most influential. He stresses the antagonism between artificial intelligence (AI) and connectionism, but apparently this has been resolved by Marvin Minsky (one of the founders of $\mathrm{AI}$ and according to Johnson "famous for his sarcasm"), who performed the unaccustomed role of a diplomat at a connectionist conference. Many, but not all, now accept that in the hierarchy of the brain, AI rules at a high level, neural nets at lower ones.

Johnson ends with a brief discussion of the philosophy of science and of mind. His heroine for the last act is, for no apparent reason Patricia Churchland, an extreme reductionist. Few of the counter arguments are given and consciousness is not mentioned.

I may be biased, but it seems odd that almost no psychological research on memory is mentioned. Psychologists have after all established that there are three different kinds of memory, which last for very different times. Moreover, even rats can connect in their memory events that are separated by a four-hour time gap. These and many other facts pose a challenge for physiological theories of the engram. Nevertheless, Johnson has written a fascinating book, which perhaps throws as much light on how science is done and on the scientists who do it as any book since The Double Helix: all it lacks is a denouement. But that would be hard to provide, because while the knights of old inhabited real castles, most workers on memory have built castles in the air.

Stuart Sutherland is in the Department of Experimental Psychology, University of Sussex, Sussex House, Falmer, Brighton BN1 9QG, UK. 